\title{
Knowledge Translation in Oncology. A Case Study
}

\author{
Francesca Dal Mas ${ }^{1}$, Helena Biancuzzi ${ }^{2}$, Maurizio Massaro ${ }^{3}$, Amelia Barcellini ${ }^{4}$, Lorenzo \\ Cobianchi ${ }^{5}$ and Luca Miceli ${ }^{6}$ \\ ${ }^{1}$ Lincoln International Business School, University of Lincoln, Lincoln, UK \\ ${ }^{2}$ Ipazia - International Observatory on Gender Research, Rome, Italy \\ ${ }^{3}$ Dipartimento di Management, Università Ca' Foscari, Venice, Italy \\ ${ }^{4}$ National Center of Oncological Hadrontherapy (Fondazione CNAO), Pavia, Italy \\ ${ }^{5}$ Dipartimento di Scienze Clinico-Chirurgiche, Diagnostiche e Pediatriche, Università degli Studi di \\ Pavia, Italy; Dipartimento di Scienze Chirurgiche, Fondazione IRCCS Policlinico San Matteo, Pavia, \\ Italy \\ IIRCCS C.R.O. (National Cancer Institute Center), Aviano, Italy
}

fdalmas@lincoln.ac.uk

helena.biancuzziuniud@outlook.it

maurizio.massaro@unive.it

amelia.barcellini@cnao.it

lorenzo.cobianchi@unipv.it

luca.miceli@cro.it

DOI: 10.34190/EJKM.18.03.002

\begin{abstract}
Knowledge translation (KT) is the ability to make knowledge accessible to different stakeholders by translating it into various contexts. Translating knowledge is particularly crucial in the healthcare sector, which is currently under significant pressure due to technological innovation, increasing demand of services by an ageing population, budget reductions, and new organisational challenges posed by the latest events like the COVID-19 pandemic. While the first definition of KT was focused on the translation of scientific research into clinical practice, other types of KT later emerged. In healthcare, while stakeholders have different skills and competencies (such as clinical scientists versus physicians or other healthcare professionals), others experience diverse emotional feelings (like the patients or their families). An effective KT allows the transfer, sharing, and creation of new knowledge, enhancing innovation and co-production dynamics. The paper employs a case study by analysing the Breast Unit of the C.R.O. National Cancer Institue of Aviano, Italy, one of the most acknowledged hospitals and research centres in Europe in the field of cancer surgery and treatments. The paper aims at studying the knowledge translation dynamics and tools by analysing the various relationships with the internal as well as the external stakeholders of the Breast Unit. Internally, knowledge translation is needed to merge the competencies of highly skilled multidisciplinary teams, which include surgeons and physicians with various specialities, researchers, psychologists, nurses and other healthcare professionals. Externally, knowledge is translated to meet the needs of patients, patients' associations, sponsors, citizens, and policymakers. Results highlight how different techniques and dynamics allow KT to happen within internal as well as external groups. Contributing to the knowledge management and knowledge translation theories, our findings open up to practical as well as research implications.
\end{abstract}

Keywords: Knowledge Translation, Healthcare, Stakeholders, Breast Cancer, Medicine

\section{Introduction}

Knowledge management is becoming a key issue in the private (Del Giudice and Maggioni, 2014; Shujahat et al., 2019; Sousa, 2013) as well as in the public sector (Massaro, Dumay and Garlatti, 2015). Several studies have investigated the relevance of knowledge and its management in healthcare organisations (Jørgensen et al., 2019; Miller, 2015; Sousa et al., 2020). Knowledge management has also been considered as a means to cope with all the challenges that the healthcare field is facing, including the introduction of new technologies like augmented reality, big data analytics and artificial intelligence (Dal Mas, Piccolo and Ruzza, 2020; Dal Mas et al., 2020b), the need to provide services to an ageing population with chronic diseases (Bowser et al., 2019; Miceli et al., 2017), the budget cuts (Massaro, Dumay and Garlatti, 2015) and last, but not least, the need to redesign the system in a "new normal" after the COVID-19 pandemic at the beginning of 2020 (Cobianchi et al., 2020b).

In this evolving scenario, the healthcare ecosystem is turning to a wide-open system (Secundo et al. 2019a) in which several different stakeholders need to engage in transferring, sharing, and creating new knowledge, enhancing innovation. While a multidisciplinary professional perspective is required in medicine and surgery (Gabel, Hilton and Nathanson, 1997; Olson, Tooman, and Alvarado, 2010; Qadan et al., 2020), there is an 
increasing call to engage the patients in the co-production of the healthcare products and services (Batalden et al., 2016; Dal Mas, et al., 2020a; Osborne and Strokosch, 2013). In such a perspective, the topic of knowledge translation is gaining increasing recognition both from academia as well as practice due to its decisive role in supporting innovation and the creation of new knowledge (Dal Mas, et al., 2020a; Simeone, Secundo and Schiuma, 2018). Knowledge translation is needed when the stakeholders involved have diverse characteristics in terms of skills, competencies, and expertise (Lemire, Souffez, and Laurendeau, 2013; Savory, 2006). Such features build relevant barriers that make it more difficult to transfer and share knowledge effectively, forcing institutions to find tools to enable the translation process.

Starting from this premise, the paper wants to investigate how knowledge is translated within a specific multidisciplinary unit of a public cancer centre located in Italy. Trying to understand the knowledge translation dynamics, the article addresses the following research question:

\section{How is knowledge translated within a high-skilled knowledge institution in the healthcare sector?}

The paper is organised as follows. The next section reports the trends in the literature regarding knowledge translation in medicine. The following section describes the methodology used, deepening the research context and data collection and analysis. Results are reported next, followed by the discussion. The conclusion section ends the paper.

\section{Literature review}

The terms "knowledge translation" recalls the concept of a foreign language which is literally translated into a different language in a divergent context (Secundo et al., 2019b). Savory (2006) stresses how the social nature of knowledge does not allow to talk about a "knowledge transfer" simply. A more comprehensive "translation" is necessary.

Knowledge translation in the healthcare sector is particularly interesting. Indeed, the healthcare ecosystem is based on the interactions of individuals and organisations into a complex adaptive environment (Jacquinet et al., 2019). Productive relationships need to be managed as part of this complex system, and interactions among various actors allow to "produce valuable, new, and unpredictable capabilities that are not inherent in any of the parts acting alone" (Plsek and Wilson, 2001, p. 746). Healthcare ecosystems have been experiencing a shift from a centralised and sequential model of value creation to a more distributed and open model (Bowser et al., 2019; Chen et al., 2019; Cobianchi, 2020b; Gordon, Perlman, and Shukla, 2017; IBM, 2013; Siemens, 2018), where citizens and patients are co-creators of their own wellbeing (Batalden et al., 2016; Bessant, Moeslein, and Kunne, 2012; Biancuzzi et al., 2020b; Dal Mas et al., 2019a; Dal Mas, Paoloni, and Lombardi, 2019; Dal Mas and Paoloni, 2019, 2020). The healthcare ecosystems usually involve a vast number of parties (patients, physicians, clinical researchers, nurses, policymakers) that share their innovation processes to incorporate knowledge flows originated from or co-produced with external stakeholders (universities, research centres, industries, governmental agencies, NGOs, public institutions) (Ardito and Messeni Petruzzelli, 2017; Cobianchi, et al., 2020a; Dal Mas et al., 2018; Gassmann, Enkel, and Chesbrough, 2010; Huizingh, 2011; Renaudin et al., 2018).

In the healthcare scenario, one of the most renown definitions of knowledge translation is the one developed by the Canadian Institutes of Health Research ${ }^{1}$, later adopted by the World Health Organization (Wallace, 2012). In this perspective, knowledge translation is defined as "the synthesis, exchange, and application of knowledge by relevant stakeholders to accelerate the benefits of global and local innovation in strengthening health systems and improving people's health."

The increasing interest towards the topic can be easily recognised through a search key named "knowledge AND translation AND healthcare OR medicine" in the title, abstract, or keywords on the scientific dataset Scopus (Massaro, Dumay, and Guthrie, 2016). Such search leads to more than 3,000 contributions, of which over 2,000 in the medical and clinical literature. The search key "knowledge translation" on PubMed leads to more than 85,000 results. The review of the literature highlights the presence of several different kinds of Knowledge Translation, according to the stakeholders involved and the aim of the transfer.

\footnotetext{
${ }^{1}$ http://www.cihr-irsc.gc.ca/e/29418.html
} 
More in details, Knowledge Translation can be seen as:

- The translation of scientific research into clinical practice (Barcellini et al., 2019, 2020; Cobianchi et al., 2016; Hogan et al., 2012; Peloso et al., 2017; Turin et al., 2018; Vitolo et al., 2019a, 2019b), which aim is to transform knowledge into real-world outcomes, like new clinical protocols, surgical techniques, or drugs;

- The translation of the physician's knowledge to the patient (Kerosuo, 2010), in order to help the patient to understand the diagnosis, the possible treatments, the side effects, supporting decisionmaking;

- The translation of the patient's knowledge and needs to the physician (Angelos, 2020; Baigorri et al., 2013), to understand the patient's situation and what may best suit him/her in terms of potential treatments;

- The translation of healthcare policies from the central government to specific units (Wallace, 2012), to allow knowledge to be translated into applicable policies, rules, and protocols;

- The translation of knowledge among organisations and professional groups (Cobianchi et al., 2020a; Straus et al., 2008), including the education of healthcare professionals (Garcia Vazquez et al., 2020; Sokol and Shaughnessy, 2018), to enhance innovation and skills development;

- The translation of healthcare policies from public agencies to citizens (Giesbrecht et al., 2009), to foster co-production of services, including good behaviours and best practices like in the case of prevention;

- The translation of clinical practices in healthcare policies (Ward et al., 2012) to translate the latest medical innovation into proper regulations, laws, and protocols.

Most of the contributions in the clinical and medical fields highlight the way specific scientific research can be translated into clinical practice and then policies. Just a few studies emphasise how different professionals (scientists, physicians with various clinical backgrounds and specialities, other healthcare professionals, managers, engineers, physicists, patients ...) may translate knowledge to each other, fostering the sharing and creation of new knowledge. This opens up to a relevant research gap, given the interdisciplinary trends in medicine, surgery, and clinical education to face the abovementioned challenges of the healthcare sector in terms of digital technologies (Dal Mas et al., 2020b; Gordon, Perlman, and Shukla, 2017; Presch et al., 2020), budget reductions (Massaro, Dumay and Garlatti, 2015), and required skills (Dal Mas, Bagarotto, and Cobianchi, 2021; Fulop et al., 2019; Groenier, Pieters, and Miedema, 2017; Schutt et al., 2017).

\section{Research method}

To investigate our research question, we apply a qualitative case study approach (Yin, 2014). According to Massaro, Dumay and Bagnoli (2019, p. 275) "qualitative methods allow researchers to discover to reveal and understand relationships between variables even within complex processes, and to illustrate the influence of the social context." The literature considers the case study methodology applicable when a how or why question is asked on present issues where the researcher has no control (Yin, 2014). Moreover, case studies permit an insightful comprehension of a real-world case (Ridder et al., 2014). To ensure transparency (Massaro, Dumay, and Bagnoli, 2019), the research context, the data collection and analysis process are explained in the next sections.

\subsection{Research context}

The case study is about the Breast Unit of the IRCCS ("Istituto di Ricovero e Cura a Carattere Scientifico" Scientific Institute for Research, Hospitalization and Health Care) C.R.O. National Cancer Institute of Aviano, a public hospital devoted to oncological pathologies located in the north-east of Italy. The C.R.O. Institute of Aviano is one of the most recognised hospitals and research centres in Europe in the field of cancer surgery and treatments, awarded the status of "International Centre of Excellence" by the Italian Ministry of Health. In one year, the Institute performs over 2,300 surgeries, more than 20,000 radiotherapy treatments, over 3,600 positron emission tomographies performed and 453,000 outpatient services ${ }^{2}$. The Institute serves as an educational and training centre for the Universities of Milan, Trieste, Udine, and Modena Reggio Emilia.

\footnotetext{
${ }^{2}$ Source: the Institute's website http://www.cro.sanita.fvg.it/, last accessed March, $7^{\text {th }}, 2020$. Numbers refer to the fiscal year 2018 .
} 
Every year, nearly 1,7 million new breast cancer cases are diagnosed worldwide. Statistics claim how 1 out of 8 women has experienced breast cancer in her life, making it one of the most relevant diseases for women all over the world (Biancuzzi et al., 2019; 2020a). Breast Units are made up of multidisciplinary teams (oncology professionals, surgeons, psychologists, nurses, ...) fully devoted to the prevention, diagnosis, treatment, and rehabilitation of breast cancer patients (Kalager et al., 2009; Plate et al., 2018; Wilson et al., 2013). Thanks to the multidisciplinary approach and knowledge (Kesson et al., 2012; Saini et al., 2012), Breast Units seem to have a higher success rate (Skinner et al., 2003; Taylor et al., 2010) in terms of survival and quality of care of their patients compared to non-specialised centres ${ }^{3}$.

\subsection{Data collection and analysis}

Data collection and analysis were made involving several stakeholders from the Institute, including physicians and oncology experts, patients, and a public policy researcher involved in one of the Breast Unit's project, named "Oncology in Motion" (Biancuzzi et al., 2019; 2020b; Dal Mas et al., 2020a). More than 30 semi-structured interviews and 20 internal meetings about the abovementioned project were carried on in the period January 2019 - February 2020. Additional material like the Institute's website and social media channels and publications devoted to the general public was collected and analysed.

The following table highlights the data collection.

Table 1: Data collection

\begin{tabular}{|c|c|}
\hline Methodology & Object \\
\hline \multirow[t]{13}{*}{ Semi-structured interviews } & Two patients \\
\hline & One manager from the administration department \\
\hline & One researcher \\
\hline & One project manager \\
\hline & One policymaker \\
\hline & One breast surgeon \\
\hline & One medical doctor (oncology) \\
\hline & One physiatrist \\
\hline & One physiotherapist \\
\hline & One fitness professional \\
\hline & One nurse \\
\hline & Two librarians \\
\hline & One of NGO's members \\
\hline \multirow[t]{3}{*}{ Qualitative and Content Analysis } & The Institute's official website \\
\hline & Social network profiles (YouTube, LinkedIn, Twitter, Facebook) \\
\hline & $\begin{array}{c}\text { Six among brochures, leaflets, and booklets from the "Oncology } \\
\text { in Motion" project }\end{array}$ \\
\hline
\end{tabular}

All the collected material has been double-checked with the scientific head and principal investigator of the project (LM). To safeguard construct validity and data triangulation (Yin, 2014), we collected data and information from various sources, besides interviews. One of the researchers is himself part of the Breast Unit team (LM); one $(A B)$ is a radiation oncologist belonging to a different cancer institution; one (LC) is an academic and oncological surgeon; one more $(\mathrm{HB})$ was involved in one specific Breast Unit project for more than one year; and two of them (FD and MM) are experts in the fields of knowledge management and public management. All the results were regularly discussed among the research team. To investigate the data, all the material was manually coded by one of the authors and then discussed within the research group.

\section{Results}

To analyse the knowledge translation flows, we first decided to map the various actors involved. In doing so, we divided the stakeholders into two different groups. One first group is represented by healthcare professionals with a common healthcare background. Most of such stakeholders work directly within the Institute. The second group included the external stakeholders, meaning actors who may not have a healthcare background, and who

\footnotetext{
${ }^{3}$ https://europadonna.it/progetti/breast-unit/le-breast-unit-in-italia/
} 
may experience not only different skills and competencies but even contrasting feelings compared to the healthcare professionals.

\subsection{Knowledge translation dynamics among the healthcare professionals group}

The healthcare professionals group includes physicians and specialists (nurses, ...) from the following departments:

- Breast Radiology

- Pathological anatomy

- Breast and Plastic Surgery

- Medical Oncology

- Radiotherapy

- Nuclear Medicine

- Oncological Psychology

- Experimental Oncology

- Genetics of Hereditary Tumors

- Biobank.

Moreover, the group includes members of the Institute's General Direction and one data manager. Given the clinical background, we decided to include in the group also the GP (General Practitioner) of the patients, despite not being part of the institute.

Our analysis shows how, despite the different skills and competencies, knowledge translation is pretty smooth among the group members, thanks to the common healthcare background. Several knowledge translation and knowledge management tools and techniques emerge.

First of all, the Institute invested in technological tools which allow to translate and share data and knowledge in a more accessible and standardised way. Electronic medical records (Ambra system) are used to store data and share information both internally and also with external professionals, like the GPs. One medical doctor involved in anaesthesia and pain medicine declared:

"Our systems need to comply with several regulations in terms of security and privacy of the patient's data. The use of electronic medical records is very expensive, still useful. We can access information anytime, and at the same time, we had to agree to a way to store and share information. In the beginning, we had some troubles in getting used to it; but now I cannot think about a better way to share patients' information with my colleagues."

Multidisciplinary teams are established, and they meet on a regular basis to discuss the most challenging clinical cases. One surgeon stated:

"Working with a multidisciplinary perspective is one of the requirements of a Breast Unit. Every case is analysed as a unique one, and each of the professionals brings his or her own expertise and opinion. Open discussions and meetings are the central part of it. Not only we can assure the best cure to our patients, but we learn from each other's expertise and experience. While the past matters, there is always something new to learn."

In-person discussions have been highlighted as an effective way to share knowledge, starting from clinical evidence and learn. The same surgeon later said:

"In-person discussions are our preferred way to share knowledge about the cases to be treated. We look at each other, and even non-verbal communication matters when we have doubts or concerns."

Beside learning-by-doing, pieces of training are planned for all the staff, both online, as well as attending external courses, conferences, and seminars to learn about the new techniques and protocols and facilitate knowledge transfer. Journal publications are encouraged, as well as the use of literature synthesis and reviews according to the Cochrane library. Another medical doctor stated: 
"We always need to keep up with what is going on in our scientific field. Not only we are pretty active in publishing, but we monitor the most relevant journals of our field. If some of us find some interesting news, we share the article with our colleagues, and we discuss results."

The members of the Breast Unit are encouraged to travel and spend visiting periods at other research centres all over the world. External visitors are welcome as a way to improve knowledge. The Director declared:

"We always host scholars and clinicians from other centers all over the world, and I strongly encourage my staff to travel and spend time at other institutions. There is always something new to learn, not only in medical terms but also from a managerial and organisational perspective."

The longevity of the members, together with a low turnover, are considered relevant to retain and share knowledge, and also mentor students or residents from universities. The quality is assessed not only internally, but also thanks to the various certifications and accreditations of the Institute. The Director underlined:

"Quality assessment is not only relevant to measure our standards, but it encourages us to manage data in a certain way. Enhancing knowledge transfer and sharing is a key element in all our assessments."

\subsection{Knowledge translation dynamics among the "external" group}

The "external" stakeholders group includes various actors who need to translate knowledge from and to the Breast Unit. The main parties of such group include:

- The patients and their families

- The citizens

- Associations which actively provide services for the Institute

- No-profit associations and NGOs

- Policymakers belonging to the central and local government and various towns and cities

- Private companies (mainly belonging to the pharmaceutical sector) which sponsor clinical trials.

As said, the lack of healthcare and clinical background, as well as the intense feelings and emotions (especially those of patients and their family members) make the knowledge translation process more challenging. Several tools and techniques are used by the Breast Unit members to translate knowledge with such stakeholders effectively

Clinical data and information are often difficult to understand. Design elements, meaning the use of sketches, graphs, cartoons, videos, are used to translate knowledge communicating to a general audience of patients but also citizens seeking for information, considering that prevention is one of the most relevant tasks of the Breast Unit. The Project Manager of "Oncology in Motion," a project devoted to the recovery of women who underwent breast cancer surgery, declared:

"The Oncology in Motion initiative required the engagement of several stakeholders who differed from skills, aims, and feelings. The use of design elements and artefacts like sketches, graphs, and pictures helped the group a lot in staying focused and cooperate in the definition of the idea, in its fine-tuning, and even in the communication to external parties."

Communication materials and documents such as brochures and leaflets were designed even co-producing the content with patients, citizens, and no-profit associations, in order to ensure the maximum results. The same Project Manager underlined:

"We put a lot of efforts in designing the project brochure. The whole project team made up of professionals and the population, including patients and citizens, wanted it to be perfect for the women who had to undergo the cure. The cooperation within the group and the design were central elements to ensure that all meaningful information and details were included, from everyday tips to easy fitness exercises to enhance the rehabilitation."

Online tools and social media channels are used to share contents with the general audience. Specific seminars, roundtables, discussions, Q\&A sessions, and information tables at local events are organised to get in touch with 
citizens, associations, private companies belonging to the healthcare industry and policymakers. A member of one of the many NGOs which regularly cooperate with the Institute declared:

"Today, the use of social media networks is a must, especially when it comes to citizens. All the initiatives are advertised and promoted via Facebook and other channels, also creating nice posts and events to remind people about the meetings and initiatives, and tagging eventual hosts or partners."

One medical doctor stated:

"The institute's Youtube channel features many of our interviews and speeches.Talking in front of a camera sometimes embarrasses me, but I do understand that this is a means to communicate with our patients and with people in general. Prevention is one of the central aims of our breast unit, and we must be effective when transferring knowledge to the general public about what should be done in order to monitor the health status. Showing our faces helps in creating one first relationship with our patients. Of course, we try to use a simple language while doing this. Our psychologists help us a lot in polishing our communication techniques."

Testimonials like athletes and celebrities are involved in disseminating ideas and information and in raising funds. The Breast Unit members are trained by the Institute's psychologists to use a simple language, metaphors, interpersonal skills and get engaged with the patients and their families during the cure and the rehabilitation path. The Director highlighted:

"One of our main goals is to be able to communicate with our patients in an effective way. We undergo training with our psychologists to be prepared to discuss with our patients - who may be young, old, educated, or not. The fact is that sometimes is not about communicating a diagnosis, but the patient needs to decide among some possible alternatives. Our duty is to make sure that the patient understands all the pros and cons and makes the best decision for her. It is not only about talking. It is also about listening. Narrative medicine is a means to make sure that we speak less and listen more, trying to understand the patients' needs and concerns. As a team, we are trying to work a lot about this."

During the clinical journey, routines and checklists are used to ensure that the knowledge is effectively translated to the patients, who contribute to the co-production of the service. One nurse said:

"Our leaflets, brochures, and publications devoted to patients and the general public are designed in a clear way, or at least we try to! Marking our patients understand what they can or cannot do or what they should do or avoid is a starting point for them to heal. Therefore, translating knowledge to them [the patients] is central to help them in their healthcare journey."

\section{Discussion}

Investigating the knowledge flows at the Breast Unit of the National Cancer Institute of Aviano, we noticed the presence of different stakeholders groups (Biancuzzi, et al., 2020a; Bowser et al., 2019; Secundo et al., 2019a).

One first group was made up of healthcare professionals, who, thanks to both tacit as well as explicit knowledge management tools, could translate knowledge more easily (Sousa et al., 2020). Dynamics within this group suggest the relevance of technological tools and routine practices (Baigorri et al., 2013; Friberger and Falkman, 2013) as knowledge enablers. Pieces of training and learning about new protocols (Aruni, Amit, and Dasgupta, 2018; Cobianchi et al., 2016; Dal Mas et al. 2019b; Vitolo et al., 2019b), publishing (McAneney et al., 2010), mobility, visiting periods at other institutes or hospitals (Conway, Dowling, and Devane, 2019) and meetings with colleagues and professionals from other centres (Olson, Tooman, and Alvarado, 2010) contribute to the accumulation and creation of new clinical knowledge.

The second group includes those stakeholders without a specific healthcare background, who often experience intense feelings engaging with the Breast Unit. The strategies employed by the Breast Unit members to translate knowledge to such stakeholders are for sure different than the ones used within the clinical team. Design (Dal Mas et al. 2020a; Simeone, Secundo and Schiuma, 2017, 2018), brochures and guides, social media channels and online tools (Dal Mas, 2019; Massaro et al., 2018; Presch et al., 2020), specific Q\&A sessions (Sokol and 
Shaughnessy, 2018), the use of a simple language (Wallace, 2012) and kindness (Tribble et al., 2008) represent tools which are capable of engaging the patients and the community (associations, private companies, sponsors, members of the local government and cities). Translating knowledge to engage external non-professional stakeholders leads to co-production as a way to co-create new knowledge and services (Batalden et al., 2016; Biancuzzi et al., 2020b). Knowledge translation appears strategic in all the aims of the Breast Unit: engaging with the community to enhance prevention, to better treat the disease, and to improve rehabilitation, leading to the wellbeing of the patients and the population.

Thus, in answering our research question "How is knowledge translated within a high-skilled knowledge institution in the healthcare sector?" we may highlight the differences between professional and nonprofessional stakeholders groups in leading the knowledge translation. While within professional groups, like the one of the Breast Unit, knowledge flows are easier to manage, better with the help of technical tools and routines, non-professional stakeholders require the use of more creative techniques like design, testimonials, social media and interpersonal skills. The team dynamics highlight the fact that permanent teams differ from temporary groups. These dynamics can be described not only starting from the fact that competencies and skills vary (the professionals belonging to the Breast Unit do have a common clinical/healthcare background and a clear working mission), but also the fact that permanent groups, which work in a completely different way than temporary teams (Massaro et al. 2019), build their own language, routines, processes, which make it easier to translate and share knowledge in an effective way. People who engage with the Breast Unit only when needed do not have enough time to do so. Therefore, more creative ways such as design and social media help to manage the skills and emotional barriers. In such a perspective, the relevance of non-technical skills emerge (Dal Mas, Bagarotto, and Cobianchi, 2021; Lepeley, 2021; Lepeley and Albornoz, 2012; Yule and Smink, 2020).

\section{Conclusions}

In concluding our work, we would like to recall the premise that inspired it. Knowledge management is a central topic for modern healthcare organisations. While healthcare institutions are more open to the engagement of several different parties, knowledge translation issues emerge. There is a need to understand which dynamics lead to the effective transfer, sharing, and creation of new knowledge. Multidisciplinary groups and teams are more and more frequent in the healthcare scenario, like in the case of Breast Units. The Aviano experience highlighted how the effectiveness in translating knowledge both among internal as well as external stakeholders might help the healthcare organisation in reaching its goals, even by involving the non-professional actors and users in co-production processes, allowing the patients to co-create their own value. In this perspective, the leading institution should ensure that appropriate knowledge translation tools and mechanisms are put in place to allow the various groups to soften up their differences and foster the sharing and creation of new knowledge.

As a polar case (Yin, 2014), the National Cancer Institute of Aviano experience may be useful to other healthcare institutions experiencing the same issues, in defining practical tools to enhance the translation of knowledge.

Like all research works, ours has some limitations. The specific context (a multidisciplinary Breast unit in a vibrant research and clinical institute located in Italy) may bias the results. Although we tried to ensure data validity and reliability, some results come from the researchers' evaluation and perspective.

Further research implications may include the detailed investigation of some of the knowledge translation techniques described in the case or comparative studies with other Breast Units or centres located in different areas.

\section{References}

Angelos, P., 2020. Interventions to improve informed consent perhaps surgeons should speak less and listen smre. JAMA Surgery, 155(1), pp. 13-14.

Ardito, L. and Messeni Petruzzelli, A., 2017. Breadth of external knowledge sourcing and product innovation: the moderating role of strategic human resource practices. European Management Journal, 35(2), pp. 261-272

Aruni, G., Amit, G. and Dasgupta, P., 2018. New surgical robots on the horizon and the potential role of artificial intelligence. Investigative and Clinical Urology, 59(4), pp. 221-222.

Baigorri, A., Villadangos, J., Astrain, J.J. and Córdoba, A., 2013. A medical knowledge management system based on expert tagging (MKMST). WIT Transactions on Information and Communication Technologies, 45, pp. 221-231.

Barcellini, A., Vitolo, V., Cobianchi, L., Peloso, A., Vanoli, A., Mirandola, A., Facoetti, A., Fiore, M.R., lannalfi, A., Vischioni, B., Cuccia, F., Ronchi, S., Bonora, M., Riva, G., Petrucci, R., D’ippolito, E., Dal Mas, F., Preda, L. and Valvo, F., 2020. Re- 
irradiation with carbon ion radiotherapy for pelvic rectal cancer recurrences in patients previously irradiated to the pelvis. In Vivo, 34(3), pp. 1547-1553.

Barcellini, A., Vitolo, V., Facoetti, A., Fossati, P., Preda, L., Fiore, M.R., Vischioni, B., lannalfi, A., Bonora, M., Ronchi, S., D'Ippolito, E., Petrucci, R., Viselner, G., Ciocca, M., Valvo, F. and Orecchia, R., 2019. Feasibility of carbon ion radiotherapy in the treatment of gynecological melanoma. In Vivo, 33(2), pp. 473-476.

Batalden, M., Batalden, P., Margolis, P., Seid, M., Armstrong, G., Opipari-arrigan, L. and Hartung, H., 2016. Coproduction of healthcare service. BMJ Quality \& Safety, 25(7), pp. 509-517.

Bessant, J., Moeslein, K. and Kunne, C., 2012. Opening up healthcare innovation: Innovation solutions for a 21st century healthcare system, AIM. London: Advanced Institute of Management Research.

Biancuzzi, H., Dal Mas, F., Barcellini, A. and Miceli, L., 2020a. La Traduzione della Conoscenza in ambito medico tra diversi stakeholders. Un caso di studio in oncologia. Recenti Progressi in Medicina, In press.

Biancuzzi, H., Dal Mas, F., Miceli, L. and Bednarova, R., 2020b. Post breast cancer coaching path: a co-production experience for women. In: P. Paoloni and R. Lombardi (Eds). 2020. Gender Studies, Entrepreneurship and Human Capital. IPAZIA 2019. Springer Proceedings in Business and Economics. Cham: Springer. pp. 11-23.

Biancuzzi, H., Miceli, L., Bednarova, R. and Garlatti, A., 2019. Post-breast cancer coaching: the synergy between health and fitness through co-production. Igiene e sanità pubblica, 75(3), pp. 181-187.

Bowser, J., Saxena, S., Fraser, H. and Marshall, A., 2019. A healthy outlook: Digital Reinvention in healthcare [online] IBM Institute for Business Value, Armonk, Available at: papers3://publication/uuid/00C50A8C-9B9B-49D3-96B8C66B960B2068 [Accessed 10 March 2020]

Chen, B., Baur, A., Stepniak, M. and Wang, J., 2019. Finding the future of care provision: the role of smart hospitals [online] McKinsey \& Company, Available at: https://www.mckinsey.com/industries/healthcare-systems-and-services/ourinsights/finding-the-future-of-care-provision-the-role-of-smart-hospitals [Accessed 1 August 2020]

Cobianchi, L., Dal Mas, F., Piccolo, D., Peloso, A., Secundo, G., Massaro, M., Takeda, A., Garcia Vazquez, A., Verde, J.M., Swanstrom, L.L., Marescaux, J., Perretta, S., Gallix, B., Dimarcq, J.-L. and Gimenez, M.E. 2020a. Digital transformation in healthcare. The challenges of translating knowledge in a primary research, educational and clinical centre. In: K.S. Soliman (Ed.), International Business Information Management Conference (35th IBIMA), IBIMA, Seville, Spain, 1-2 April 2020, pp. 6877-6888.

Cobianchi, L., Peloso, A., Vischioni, B., Panizza, D., Fiore, M.R., Fossati, P., Vitolo, V., lannalfi, A., Ciocca, M., Brugnatelli, S., Dominioni, T., Bugada, D., Maestri, M., Alessiani, M., Valvo, F., Orecchia, R. and Dionigi, P.2016. Surgical spacer placement prior carbon ion radiotherapy ( CIRT ): an effective feasible strategy to improve the treatment for sacral chordoma. World Journal of Surgical Oncology, 14(211), pp. 1-9.

Cobianchi, L., Pugliese, L., Peloso, A., Dal Mas, F. and Angelos, P., 2020b. To a new normal: surgery and COVID-19 during the transition phase. Annals of Surgery, 272, pp. e49-e51.

Conway, A., Dowling, M. and Devane, D., 2019. Implementing an initiative promote evidence-informed practice: Part 2. Healthcare professionals' perspectives of the evidence rounds programme. BMC Medical Education, 19(1), pp. 1-17.

Dal Mas, F., 2019. The relationship between intellectual capital and sustainability: an analysis of practitioner's thought. In: F. Matos, V. Vairinhos, P.M. Selig and L. Edvinsson (Eds) 2019. Intellectual Capital Management as a Driver of Sustainability: Perspectives for Organizations and Society. Cham: Springer. pp. 11-24.

Dal Mas, F., Bagarotto, E.M. and Cobianchi, L., 2021. Soft Skills effects on Knowledge Translation in healthcare. Evidence from the field. In: Lepeley, M.T., Beutell, N., Abarca, N. and Majluf, N., Ed. 2021. Soft skills for human centered management and global sustainability., London: Routledge.

Dal Mas, F., Biancuzzi, H., Massaro, M. and Miceli, L., 2020a. Adopting a knowledge translation approach in healthcare coproduction. A case study. Management Decision, In Press, doi:10.1108/MD-10-2019-1444.

Dal Mas, F., Massaro, M., Lombardi, R. and Garlatti, A., 2019a. From output to outcome measures in the public sector. A structured literature review. International Journal of Organizational Analysis, 27(5), pp. 1631-1656.

Dal Mas, F. and Paoloni, P., 2019. A relational capital perspective on social sustainability. The case of female entrepreneurship in Italy. Measuring Business Excellence, 24(1), pp. 114-130.

Dal Mas, F. and Paoloni, P., 2020. Female start-ups in Italy : a relational capital. In: P. Paoloni and R. Lombardi (Eds). Gender Studies, Entrepreneurship and Human Capital. IPAZIA 2019. Springer Proceedings in Business and Economics. Cham: Springer. pp. 75-87.

Dal Mas, F., Paoloni, P. and Lombardi, R., 2019. Wellbeing of women entrepreneurship and relational capital, a case study in Italy. In: M.T. Lepeley, K. Kuschel, E. Eijdenberg, and N.Pouw (Eds). 2019. Exploring Wellbeing among Women in Entrepreneurship. A Global Perspective. London: Routledge. pp. 232-243.

Dal Mas, F., Piccolo, D., Cobianchi, L., Edvinsson, L., Presch, G., Massaro, M., Skrap, M., Ferrario di Tor Vajana, A., D'Auria, S. and Bagnoli, C., 2019b. The effects of artificial intelligence, robotics, and industry 4.0 technologies. Insights from the Healthcare sector. In: Proceedings of the first European Conference on the impact of Artificial Intelligence and Robotics, Oxford, United Kingdom, 31 October - 1 November 2019. Academic Conferences and Publishing International Limited, pp. 88-95.

Dal Mas, F., Piccolo, D., Edvinsson, L., Skrap, M. and D'Auria, S., 2020b. Strategy innovation, intellectual capital management and the future of healthcare. The case of Kiron by nucleode. In: F. Matos, V. Vairinhos, I. Salavisa, L. Edvinsson and M. Massaro, (Eds). 2020. Knowledge, People, and Digital Transformation: Approaches for a Sustainable Future. Cham: Springer. pp. 119-131. 
Dal Mas, F., Piccolo, D. and Ruzza, D., 2020. Overcoming cognitive bias through intellectual capital management. The case of pediatric medicine. In: P.Ordonez de Pablos and L. Edvinsson (Eds) 2020. Intellectual Capital in the Digital Economy. London: Routledge. pp. 123-133.

Dal Mas, F., Renaudin, M., Garlatti, A. and Massaro, M. 2018. Towards a social Knowledge Management in a knowledgeintensive public organization. In: Proceedings of the 15th International Conference on Intellectual Capital, Knowledge Management And Organisational Learning ICICKM 2018, Cape Town, South Africa, 20-30 November 2018. Academic Conferences and Publishing International Limited, pp. 40-48.

Friberger, M.G. and Falkman, G., 2013. Collaboration processes, outcomes, challenges and enablers of distributed clinical communities of practice. Behaviour \& Information Technology, 32(6), pp. 519-531.

Fulop, E.L., Kippist, L., Dadich, A., Hayes, K., Karimi, L. and Symth, A., 2019. What makes a team brilliant? An experiential exploration of positivity within healthcare. Journal of Management and Organization, 25(4), pp. 591-612.

Gabel, M., Hilton, N.E. and Nathanson, S.D., 1997. Multidisciplinary breast cancer clinics. Do they work ? Cancer, 79(12), pp. 2380-2384.

Garcia Vazquez, A., Verde, J.M., Dal Mas, F., Palermo, M., Cobianchi, L., Marescaux, J., Gallix, B., Dallemagne, B., Perretta, S. and Gimenez, M.E., 2020. Image-guided surgical e-learning in the post-COVID-19 pandemic era: what is next? Journal of Laparoendoscopic \& Advanced Surgical Techniques, In Press. doi.org/10.1089/lap.2020.0535

Gassmann, O., Enkel, E. and Chesbrough, H., 2010. The future of open innovation. R\&D Management, 40(3), pp. $213-221$.

Giesbrecht, M., Crooks, V.A., Schuurman, N. and Williams, A., 2009. Spatially informed knowledge translation: Informing potential users of Canada's Compassionate Care Benefit. Social Science \& Medicine, 69(3), pp. 411-419.

Del Giudice, M. and Maggioni, V., 2014. Managerial practices and operative directions of knowledge management within inter-firm networks: a global view. Journal of Knowledge Management, 18(5), pp. 841-846.

Gordon, R., Perlman, M. and Shukla, M., 2017. The hospital of the future: how digital technologies can change hospitals globally, [online] Deloitte, Available at: https://www2.deloitte.com/content/dam/Deloitte/global/Documents/LifeSciences-Health-Care/us-Ishc-hospital-of-the-future.pdf. [Accessed 1 August 2020]

Groenier, M., Pieters, J.M. and Miedema, H.A.T., 2017. Technical medicine: designing medical technological solutions for improved health care. Medical Science Educator, 27(4), pp. 621-631.

Hogan, A.R., Doni, M., Damaris Molano, R., Ribeiro, M.M., Szeto, A., Cobianchi, L., Zahr-Akrawi, E., Molina, J., Fornoni, A., Mendez, A.J., Ricordi, C., Pastori, R.L. and Pileggi, A., 2012. Beneficial effects of ischemic preconditioning on pancreas cold preservation. Cell Transplantation, 21(7), pp. 1349-1360.

Huizingh, E., 2011. Open innovation: state of the art and future perspectives. Technovation, 31(1), pp. 2-9.

IBM., 2013. The Digital hospital evolution. Creating a framework for the healthcare system of the future, [online] Somers, Available at: http://www.himss.eu/sites/himsseu/files/education/whitepapers/IBM Digital Hospital Evolution GBW03203-USEN-00.pdf. [Accessed 1 August 2020]r

Jacquinet, M., Curado, H., Nobre, A.L., Sousa, M.J., Arraya, M., Pimenta, R. and Martins, A.E., 2019. Management of tacit knowledge and the issue of empowerment of patients and stakeholders in the health care sector. In: Information Resources Management Association. 2019. Healthcare policy and reform: concepts, methodologies, tools and applications, Hershey: IGI Global.

Jørgensen, R., Scarso, E., Edwards, K. and Ipsen, C., 2019. Communities of practice in healthcare: a framework for managing knowledge sharing in operations. Knowledge and Process Management, 26(2), pp. 152-162.

Kalager, M., Haldorsen, T., Bretthauer, M., Hoff, G., Thoresen, S.O. and Adami, H.O., 2009. Improved breast cancer survival following introduction of an organized mammography screening program among both screened and unscreened women: A population-based cohort study. Breast Cancer Research, 11(4), pp. 1-9.

Kerosuo, H., 2010. Lost in translation: a patient-centred experience of unintegrated care. International Journal of Public Sector Management, 23(4), pp. 372-380.

Kesson, E.M., Allardice, G.M., George, W.D., Burns, H.J.G. and Morrison, D.S., 2012. Effects of multidisciplinary team working on breast cancer survival: Retrospective, comparative, interventional cohort study of 13722 women. BMJ (Online), 344(7856), pp. 19-21.

Lemire, N., Souffez, K. and Laurendeau, M.C., 2013. Facilitating a knowledge translation process. Knowledge review and facilitation tool. Quebec: Institut Publique de Santé du Quebec.

Lepeley, M.T., 2021. Soft skills: the language of human centered management. In: M.T. Lepeley, N. Beutell, N. Abarca and N. Majluf )Eds). 2021. Soft skills for human centered management and global sustainability, London: Routledge.

Lepeley, M.T. and Albornoz, C.A., 2012. Advancing people skills for 21st Century business education in Chile. In: I. Alon, V. Jones and J. Mclntyre (Eds) 2012. Innovation in business education in emerging countries. New York: Palgrave Macmillan.

Massaro, M., Dal Mas, F., Bontis, N. and Gerrard, B., 2019. Intellectual capital and performance in temporary teams. Management Decision, 58(3), pp. 410-427.

Massaro, M., Dumay, J. and Bagnoli, C., 2019. Transparency and the rhetorical use of citations to Robert Yin in case study research. Meditari Accountancy Research, 27(1), pp. 44-71.

Massaro, M., Dumay, J. and Garlatti, A., 2015. Public sector knowledge management: a structured literature review. Journal of Knowledge Management, 19(3), pp. 530-558.

Massaro, M., Dumay, J., Garlatti, A. and Dal Mas, F., 2018. Practitioners' views on intellectual capital and sustainability: from a performance-based to a worth-based perspective. Journal of Intellectual Capital, 19(2), pp. 367-386. 
Massaro, M., Dumay, J.C. and Guthrie, J., 2016. On the shoulders of giants: undertaking a structured literature review in accounting. Accounting, Auditing and Accountability Journal, 29(5), pp. 767-901.

McAneney, H., McCann, J., Prior, L., Wilde, J. and Kee, F., 2010. Translating evidence into practice: a shared priority in public health? Social Science \& Medicine, 70, pp. 1492-1500.

Miceli, L., Bednarova, R., Di Cesare, M., Santori, E., Spizzichino, M., Di Minco, L., Botti, R., Casciello, M. and Della Rocca, G., 2017. Outpatient therapeutic chronic opioid consumption in Italy: a one-year survey. Minerva Anestesiologica, 83(1), pp. 33-40.

Miller, L.M., 2015. E-health: knowledge generation, value intangibles, and intellectual capital. International Journal of Healthcare Management, 8(2), pp. 100-111.

Olson, C.A., Tooman, T.R. and Alvarado, C.J., 2010. Knowledge systems, health care teams, and clinical practice: a study of successful change. Advances in Health Sciences Education, 15(4), pp. 491-516.

Osborne, S.P. and Strokosch, K., 2013. It takes two to tango? Understanding the co-production of public services by integrating the services management and public administration perspectives. British Journal of Management, 24(S1), pp. S31-S47.

Peloso, A., Viganò, J., Vanoli, A., Dominioni, T., Zonta, S., Bugada, D., Bianchi, C.M., Calabrese, F., Benzoni, I., Maestri, M., Dionigi, P. and Cobianchi, L., 2017. Saving from unnecessary pancreaticoduodenectomy . Brunner' s gland hamartoma : case report on a rare duodenal lesion and exhaustive literature review. Annals of Medicine and Surgery, 17, pp. 43-49.

Plate, S., Emilsson, L., Söderberg, M., Brandberg, Y. and Wärnberg, F., 2018. High experienced continuity in breast cancer care is associated with high health related quality of life. BMC Health Services Research, 18(1), pp. 1-8.

Plsek, P. and Wilson, T., 2001. Complexity, leadership, and management in healthcare organisations. British Medical Journal, 323(7315), pp. 746-749.

Presch, G., Dal Mas, F., Piccolo, D., Sinik, M. and Cobianchi, L., 2020. The World Health Innovation Summit (WHIS) platform for sustainable development; from the digital economy to knowledge in the healthcare sector. In: P> Ordonez de Pablos and L. Edvinsson (Eds) 2020. Intellectual Capital in the Digital Economy. London: Routledge. pp. 19-28.

Qadan, M., Hong, T.S., Tanabe, K.K., Ryan, D.P. and Lillemoe, K.D., 2020. A multidisciplinary team approach for triage of elective cancer surgery at the Massachusetts General Hospital during the novel Coronavirus COVID-19 outbreak. Annals of Surgery, 272(1), e20-e21.

Renaudin, M., Dal Mas, F., Garlatti, A. and Massaro, M., 2018. Knowledge Management and cultural change in a knowledge-intensive public organization. In: D. Remeniy (Ed 2018. 4th Knowledge Management and Intellectual Capital Excellence Awards, Reading: Academic Conferences and Publishing International Limited. pp. 85-96.

Ridder, H.-G., Hoon, C. and McCandless Baluch, A., 2014. Entering a dialogue: positioning case study findings towards theory. British Journal of Management, 25(2), pp. 373-387.

Saini, K.S., Taylor, C., Ramirez, A.J., Palmieri, C., Gunnarsson, U., Schmoll, H.J., Dolci, S.M., Ghenne, C., Metzger-Filho, O., Skrzypski, M., Paesmans, M., Ameye, L., Piccart-Gebhart, M. J. and de Azambuja, E., 2012. Role of the multidisciplinary team in breast cancer management: results from a large international survey involving 39 countries. Annals of Oncology, 23(4), pp. 853-859.

Savory, C., 2006. Translating knowledge to build technological competence. Management Decision, 44(8), pp. 1052-1075.

Schutt, S., Holloway, D., Linegar, D. and Deman, D., 2017. Using simulated digital role plays to teach healthcare 'soft skills. In: SeGAH 2017, IEEE 5th International Conference on Serious Games and Applications for Health, Perth, Australia, 2-4 April 2017. pp. 1-6.

Secundo, G., Toma, A., Schiuma, G. and Passiante, G., 2019a. Knowledge transfer in open innovation: aclassification framework for healthcare ecosystems. Business Process Management Journal, 25(1), pp. 144-163.

Secundo, G., Del Vecchio, P., Simeone, L. and Schiuma, G., 2019b. Creativity and stakeholders' engagement in open innovation: design for knowledge translation in technology-intensive enterprises. Journal of Business Research, In press.

Shujahat, M., Sousa, M.J., Hussain, S., Wang, M. and Umer, M., 2019. Translating the impact of knowledge management processes into knowledge-based innovation: the neglected and mediating role of knowledge-worker productivity. Journal of Business Research, 94, pp. 442-450.

Siemens, 2018. Smart hospitals - smart healthcare; creating perfect places to heal. [online] Available at: https://new.siemens.com/global/en/products/buildings/markets/smart-hospitals.html [Accessed 1 August 2020]

Simeone, L., Secundo, G. and Schiuma, G., 2017. Adopting a design approach to translate needs and interests of stakeholders in academic entrepreneurship : the MIT Senseable City Lab case. Technovation, 64-65(July), pp. 58-67.

Simeone, L., Secundo, G. and Schiuma, G., 2018. Arts and design as translational mechanisms for academic entrepreneurship : the metaLAB at Harvard case study. Journal of Business Research, 85, pp. 434-443.

Skinner, K.A., Helsper, J.T., Deapen, D., Ye, W. and Sposto, R., 2003. Breast cancer: do specialists make a difference? Annals of Surgical Oncology, 10(6), pp. 606-615.

Sokol, R.G. and Shaughnessy, A.F., 2018. Making the most of continuing medical education: evidence of transformative learning during a course in evidence-based medicine and decision making. Journal of Continuing Education in the Health Professions, 38(2), pp. 102-109.

Sousa, M.J., 2013. Knowledge integration in problem solving processes. In: Á. Rocha, A.M. Correia, T. Wilson and K. A. Stroetmann (Eds). Advances in Intelligent Systems and Computing, Cham: Springer. pp. 97-1 09. 
Sousa, M.J., Dal Mas, F., Garcia-Perez, A. and Cobianchi, L, 2020. Knowledge in transition in healthcare. European Journal of Investigation in Health, Psychology and Education, 10(3), pp. 733-748.

Straus, S.E., Graham, I.D., Taylor, M. and Lockyer, J., 2008. Development of a mentorship strategy: a knowledge translation case study. Journal of Continuing Education in the Health Professions, 28(3), pp. 117-122.

Taylor, C., Munro, A.J., Glynne-Jones, R., Griffith, C., Trevatt, P., Richards, M. and Ramirez, A.J., 2010. Multidisciplinary team working in cancer: what is the evidence? British Medical Journal, 340(7749), pp. 743-745.

Tribble, D.S.C., Gallagher, F., Bell, L., Caron, C., Godbout, P., Leblanc, J., Morin, P., Xhignesse, M., Voyer, L. and Couture, M., 2008. Empowerment interventions, knowledge translation and exchange: perspectives of home care professionals, clients and caregivers. BMC Health Services Research, 8, pp. 1-9.

Turin, I., Delfanti, S., Ferulli, F., Brugnatelli, S., Tanzi, M., Maestri, M., Cobianchi, L., Lisini, D., Luinetti, O., Todisco, R., Pedrazzoli, P. and Montagna, D., 2018. In vitro killing of colorectal carcinoma cells by autologous activated NK cells is boosted by anti-epidermal growth factor receptor-induced ADCC regardless of RAS mutation status. Journal of Immunotheraphy, 41(4), pp. 190-200.

Vitolo, V., Barcellini, A., Fossati, P., Fiore, M.R., Vischioni, B., lannalfi, A., Facoetti, A., Bonora, M., Ronchi, S., D’Ippolito, E., Petrucci, R., Viselner, G., Preda, L., Ciocca, M., Valvo, F. and Orecchia, R., 2019.a Carbon ion radiotherapy in the management of unusual liposarcomas: a case report. In Vivo, 33(2), pp. 529-533.

Vitolo, V., Cobianchi, L., Brugnatelli, S., Barcellini, A., Peloso, A., Facoetti, A., Vanoli, A., Delfanti, S., Preda, L., Molinelli, S., Klersy, C., Fossati, P., Orecchia, R. and Valvo, F., 2019b. Preoperative chemotherapy and carbon ions therapy for treatment of resectable and borderline resectable pancreatic adenocarcinoma : a prospective, phase II , multicentre , single-arm study. BMC Cancer, 19(922), pp. 1-7.

Wallace, B.C., 2012. Controversies in knowledge translation for community-based drug treatment: the need to the end policies of the war on drugs and mass incarceration of drug offenders to achieve health equity. Journal of Urban Health, 89(6), pp. 894-904.

Ward, V., Smith, S., House, A. and Hamer, S., 2012. Exploring knowledge exchange: a useful framework for practice and policy. Social Science \& Medicine, 74, pp. 297-304.

Wilson, A.R.M., Marotti, L., Bianchi, S., Biganzoli, L., Claassen, S., Decker, T., Frigerio, A., Goldhirsch, A., Gustafsson, E. G., Mansel, R. E., Orecchia, R., Ponti, A., Poortmans, P., Regitnig, P., Rosselli Del Turco, M., Rutgers, E. J.T., Van Asperen, C., Wells, C.A., Wengström, Y. and Cataliotti, L., 2013. The requirements of a specialist breast Centre. European Journal of Cancer, 49(17), pp. 3579-3587.

Yin, R.K., 2014. Case Study Research: Design and Methods. 5th ed. Thousand Oaks, CA: Sage.

Yule, S. and Smink, D.S., 2020. Non-technical skill countermeasures for pandemic response. Annals of Surgery, 272(3), pp. e213-e215. 